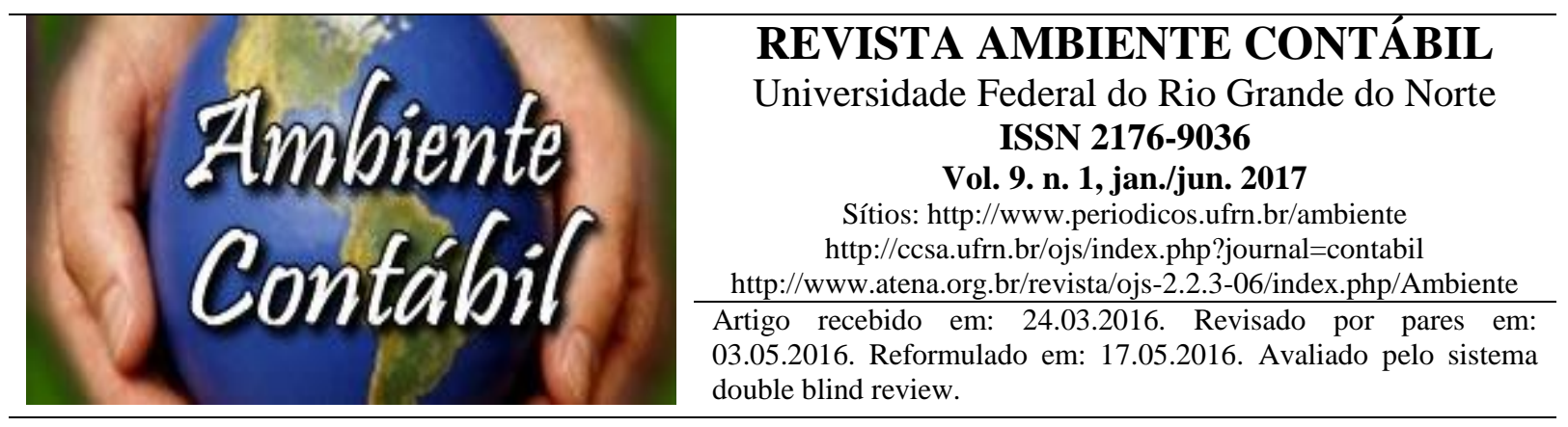

\title{
EMPREGO DA TÉCNICA DE MAPAS CONCEITUAIS EM DISCIPLINAS DE CONTABILIDADE COM ABORDAGEM GERENCIAL
}

\section{APPLICATION OF CONCEPTUAL MAPS TECHNIQUE IN ACCOUNTING DISCIPLINES WITH MANAGEMENT APPROACH}

\section{APLICACIÓN DE LA TÉCNICA DE MAPAS CONCEPTUALES EN DISCIPLINAS DE CONTABILIDAD CON ENFOQUE DE GESTIÓN}

\section{Autores}

\section{Yumara Lúcia Vasconcelos}

Pós-doutorado em andamento (direitos humanos) - Doutora em Administração / Universidade Federal da Bahia (UFBA) - Mestrado em contabilidade / Fundação Visconde de Cairu (FVC) - Especialização em finanças / Universidade Cidade de São Paulo (UINICD). Especialização em EAD e tecnologias / Universidade Cidade de são Paulo (UNICID) - Professora do Programa de Pós-graduação em Controladoria da Universidade Federal Rural de Pernambuco (UFRPE). Endereço: Rua Antônio de Castro, n.27, Edf. Esmeralda, Apto 602, Casa amarela, Recife-PE - Brasil. Telefone: (81) 3320-5403.

E-mail: yumaravasconcelos@gmail.com

\section{Ricardo Henrique Miranda de Araújo}

Mestrado do Programa de Pós-graduação em Controladoria da Universidade Federal Rural de Pernambuco (UFRPE). Endereço: Rua Professora Ângela Pinto, 97, Torre, Recife-PE -

Brasil. Telefone: (81) 3320-5403.

E-mail: rhenriquema@yahoo.com.br

\section{RESUMO}

Essa pesquisa objetivou discutir os benefícios proporcionados pelo emprego da técnica de elaboração de mapas conceituais na prática de ensino-aprendizagem. Pesquisa qualitativa de natureza exploratória, apoiou-se nos resultados de uma pesquisa-ação, analisados segundo os paradigmas entregues pela revisão de literatura. As conclusões apontam para o reconhecimento da utilidade da ferramenta no processo didático-pedagógico. A técnica revelou-se útil ao empreendimento de ações pedagógicas socializantes e individualizantes, desenvolvendo habilidades sociais, de comunicação, negociação e liderança. Sua flexibilidade inerente a coloca em posição de conformar-se a diferentes propósitos de aprendizagem e disciplinas, fomentando a iniciativa e autonomia discente.

Palavras-chave: mapas conceituais, aprendizagem significativa, técnicas de ensino. 
Revista Ambiente Contábil - ISSN 2176-9036 - UFRN - Natal-RN. v. 9. n. 1, p. 117 - 143, jan./jun. 2017.

\begin{abstract}
This research aimed to discuss the benefits provided by the use of conceptual maps technique in teaching-learning practice. Qualitative research of exploratory nature, supported by the results of an action research, analyzed according to the paradigms provided by the literature review. The findings point to the recognition of the usefulness of the tool in the teachinglearning process. The technique has proved useful with the intent of socializing and individualizing educational activities, developing social, communication, negotiation and leadership skills. Its inherent flexibility puts it in a position to conform to different purposes of learning and disciplines, fostering the initiative and autonomy of student.
\end{abstract}

Keywords: conceptual maps, meaningful learning, teaching techniques.

\title{
RESUMEN
}

Esta investigación tuvo como objetivo discutir los beneficios que ofrece la aplicación de la técnica mapas conceptuales en la práctica de enseñanza-aprendizaje. La investigación cualitativa de carácter exploratorio, se basa en los resultados de una investigación-acción, analizados de acuerdo a los paradigmas entregados por el revisión de la literatura. Los resultados apuntan al reconocimiento de la utilidad de la herramienta en el proceso de enseñanza-aprendizaje. La técnica se reveló útil para la intención de las actividades educativas de individualización y socialización, el desarrollo de habilidades sociales, comunicación, negociación y liderazgo. Su flexibilidad inherente pone en condiciones de cumplir con diferentes propósitos de aprendizaje y disciplinas, encorajando la iniciativa y autonomía de los estudiantes.

Palabras clave: mapas conceptuales, aprendizaje significativo, técnicas de enseñanza.

\section{INTRODUÇÃO}

Mostra-se crescente a utilização de representações gráficas como parte das estratégias de ensino, com o propósito de estruturar o conhecimento. O uso de representações ou objetos gráficos como recurso de comunicação não é recente, remontando a antiguidade. Na préhistória, as pinturas rupestres eram utilizadas para representar ideias, mensagens e conhecimentos (pictogramas). A mensagem visual permanece viva na atualidade, quadro que exige pessoas 'visualmente alfabetizadas', portanto, capazes de manejar e correlacionar imagens a significados mais amplos (ARENAS, 2005).

Os mapas conceituais, alternativa clássica de representação, consistem em diagramas de conteúdo que, relacionados e dispostos hierárquica ou logicamente, compõem conceitos. Comunicam, portanto, uma organização conceitual estruturada como uma rede semântica. Essa representação tem efeito de síntese, pois, inclui apenas as ideias fundamentais concernentes ao conteúdo ou elementos essenciais de um conceito (ARENAS, 2005).

Dispostos de modo lógico e visual, esses diagramas refletem os significados atribuídos pelos seus autores, traduzindo a maneira como os conhecimentos são percebidos, organizados e alocados nas às interpretações do sujeito (TAVARES, 2007; MOREIRA, BUCHWEITZ, 1987; MOREIRA, ROSA, 1986; VEIGA, 2013; ARENAS, 2005; VASCONCELOS, 2015).

Alcançam diferentes tipos de conhecimento daquele declarativo (que tem como ponto de partida o reconhecimento de uma ideia, objeto ou fenômeno) ao procedimental (voltado para a solução de problemas, planejamento e tomada de decisão) e estrutural (conceitos, seus desdobramentos e intersecções) (AMORETTI, 2001). De fato,

O mapa conceitual representa, simultaneamente, o processo de organização do conhecimento, através das relações (links) e o produto, através dos conceitos (nós). Assim, mais do que a relação entre o linguístico e o visual 
Revista Ambiente Contábil - ISSN 2176-9036 - UFRN - Natal-RN. v. 9. n. 1, p. 117 - 143, jan./jun. 2017.

está a interação entre os seus objetos e os seus códigos. (AMORETTI, 2001, p. 49).

As pessoas organizam seus conceitos de modo diferente, tendo em vista que cada construção mobiliza experiências prévias do indivíduo, suas crenças, valores, emoções, repertório de vocabulário e conhecimentos.

Os mapas conceituais compõem-se graficamente por retângulos ou quadrados e linhas retas na forma de setas, dispostas de modo a sinalizar a sequência do raciocínio. Essas linhas são interrompidas para acolher as palavras ou expressões de enlace. Na elaboração desses mapas, os elementos conceituais integram esses diagramas. As relações estabelecidas são enunciadas por meio de expressões de ligação, preposições, locuções ou verbos, posicionados nos intervalos das linhas que conectam as formas (ARENAS, 2005; NOVAK, GOWIN, 1988).

Essas 'palavras-elo' são a amálgama necessária à promoção da unidade de sentido atribuído ao objeto de aprendizagem conceituado, promovendo o enlace conceitual (GAVA, MENEZES, CURY, 2003; ARENAS, 2005; NOVAK, GOWIN, 1988).

Os mapas conceituais são utilizados para promover a sinergia e integração entre conceitos distintos, os quais podem ser organizados de forma hierárquica ou não, dependendo da perspectiva do autor, seus pontos de vista, referências valorativas, sequência estabelecida e importância atribuída às unidades conceituais (ARAÚJO, MENEZES, CURY, 2002; BARBOSA, 2005; VEIGA, 2013; ARENAS, 2005; NOVAK, GOWIN, 1988).

A relevância atribuída pelo aluno a um determinado conteúdo não converge necessariamente àquela proposta pelo professor. Os mapas tendem a revelar sentidos e entendimentos distintos, enriquecendo a prática pedagógica. A confluência de significados reclama, diálogo, sensibilização, mobilização de argumentos e negociação (VEIGA, 2013; NOVAK, GOWIN, 1988; MOREIRA, 2007; VASCONCELOS, 2015) .

Em síntese, os mapas promovem pontes (associações) entre significados, classificações e associações com experiências pretéritas do indivíduo e seus pares, trazendo à superfície suas intencionalidades, dúvidas, emoções, curiosidades, opiniões, inclinações e descobertas. De igual forma, estabelecem comparações, onde elementos da realidade são adicionados às estruturas apresentadas, quadro que lhe confere peculiaridade contextual (MOREIRA, 2007; VASCONCELOS, 2015).

As relações estabelecidas podem ser históricas, associativas, temporais ou causais, o que reforça sua propriedade lógica. Assim, o mapeamento cognitivo tem se revelado eficaz quando alocado às rotinas de ensino-aprendizagem, avaliação e pesquisa, motivação principal dos autores à elaboração desse trabalho (VEIGA, 2013; NOVAK, GOWIN, 1988; VASCONCELOS, 2015).

A técnica se instala no processo didático disponibilizando um recurso instrumental que explora interesses, predisposições, saberes e expectativas do aprendente. A mobilização dessas subjetividades tende a criar um ambiente favorável aos movimentos de aprendizagem, estimulando a expressão de suas vontades, competências e até, dificuldades, preconceitos e resistências, lançando uma reflexão pertinente acerca de quem é o aprendente, especificamente seu perfil. A técnica promove um diálogo do aprendente consigo mesmo, configurando-se como instrumento de emancipação e autogestão do conhecimento (VEIGA, 2013; NOVAK, GOWIN, 1988).

Ante o exposto, reconhecida a relevância do instrumento para a prática pedagógica, a questão problematizante que se coloca nesse trabalho é: a técnica de mapeamento conceitual potencializa a aprendizagem?

Acredita-se que a representação imagética torna a aprendizagem mais eficaz, no que concerne ao alcance dos objetivos pedagógicos propostos pelos docentes, tendo em vista que símbolos e imagens externalizam emoções, entendimentos e sentimentos (MEZIROW, 2015). 
Revista Ambiente Contábil - ISSN 2176-9036 - UFRN - Natal-RN. v. 9. n. 1, p. 117 - 143, jan./jun. 2017.

Complementarmente, admitindo-se uma contribuição efetiva da técnica para o fenômeno da aprendizagem, como os discentes a percebem e valorizam? De que maneira o 'pensamento' do sujeito aprendente, acerca dos objetos de aprendizagem, é estruturado? Quais elementos contextuais são adicionados a essa construção? Os mapas conceituais revelam o modus dessa elaboração (sequência lógica, critérios, tendências)? A técnica serve aos propósitos de avaliação? A expectativa é que a análise dos mapas conceituais oportunize uma resposta satisfatória a essas indagações.

O objetivo geral desse estudo, sem a pretensão de generalizar, é obter evidências acerca do valor pedagógico dos mapas conceituais para a potenciação da aprendizagem. Nesse intento, serão elencados os benefícios proporcionados pelo emprego da técnica de elaboração de mapas conceituais na prática de ensino-aprendizagem.

A aprendizagem repercute no desenvolvimento cognitivo, razão pela qual tem merecido a atenção de pesquisadores, reforçando a justificativa de realização desse trabalho (ROMAN, 2005).

O artigo está estruturado nas seguintes seções: introdução; referencial teórico, que apresenta os fundamentos que respondem às lacunas problematizadas; materiais e métodos, descrevendo os procedimentos metodológicos empreendidos na consecução dos propósitos dessa pesquisa; apresentação; e discussão de resultados e considerações finais. O referencial teórico apresenta o conceito, classificação e características dos mapas conceituais, ressaltando aspectos da aprendizagem significativa. Igualmente, desvela os benefícios pedagógicos relativos à aplicação da técnica de mapeamento no processo de ensino, pesquisa e avaliação.

\section{REFERENCIAL TEÓRICO}

Nesta seção serão desenvolvidos os conteúdos principais e transversais que compõem o eixo temático, objeto desse estudo.

\subsection{PROCESSO ENSINO-APRENDIZAGEM E APRENDIZAGEM SIGNIFICATIVA}

A relação entre professor e aluno é caracterizada de acordo com a ênfase atribuída ao ensino e/ou aprendizagem, que são os elementos norteadores essenciais dessa relação e que compõem um processo dual e dialógico. Eventual assimetria de atenção (ao ensino ou a aprendizagem) define o formato das estratégias adotadas pelo docente, a experiência de significação, seu desempenho, a qualidade da comunicação e o estilo correspondente (ABRAHÃO. 2008; RUIZ, 2006).

O ensino sempre visa a aprendizagem, e nesse intento, a autorealização do indivíduo e seu crescimento pessoal; dito de outra forma, o ensino deve voltar-se para a aprendizagem da pessoa em sua integralidade. A inexistência de sintonia e direção entre esses elementos (ações de ensino e aprendizagem) ensejam práticas contraproducentes e desarticuladas das demandas e expectativas desse processo. Assim, concebe-se a aprendizagem sem a mediação do professor, mas não, o inverso (ABRAHÃO, 2008).

Em relação ao papel do professor, Ruiz (p. 10,2006) adverte que sua prática “(...) deve centrar-se nos propósitos de propiciar os meios e facilitar aprendizagem. Em suma, ensinar menos e permitir que o estudante aprenda mais". O autor ressalta, nessas linhas, a necessidade de espaço para a aprendizagem (tempo de construção). Os momentos da relação pedagógica devem ser respeitados. Em confluência a esse ponto de vista, entende-se que a educação deve ser voltada direcionada ao despertamento da autonomia e reflexão, jamais para a dependência acrítica e subserviente, porque dá servilidade intelectual origina-se a apatia do conformismo e o atraso social. Educa-se para a emancipação e liberdade (FREIRE, 1996). 
Revista Ambiente Contábil - ISSN 2176-9036 - UFRN - Natal-RN. v. 9. n. 1, p. 117 - 143, jan./jun. 2017.

O autor reconhece a temporalidade e a necessidade do reconhecimento dos espaços do ensino e aprendizagem, incentivando a independência e o desenvolvimento de competências linguísticas e comunicativas (escutar, escrever, ler, especialmente, argumentar), as quais definem o sucesso desse empreendimento, fortalecendo a posição do sujeito diante do mundo (RUIZ, 2006).

Quando a aprendizagem se viabiliza pelo ensino,

O processo ensino-aprendizagem só pode ser analisado como uma unidade, pois ensino e aprendizagem são faces de uma mesma moeda; nessa unidade, a relação interpessoal professor-aluno é um fator determinante. Esses atores são concretos, históricos, trazendo a bagagem que o meio lhes ofereceu até então; (...) processo que é aberto e permanente. (MAHONEY, ALMEIDA, 2005, p. 12).

O ensino, nessa relação, atende sistematicamente às demandas dos objetivos de aprendizagem, traduzindo dentre outras, as competências propositivas e argumentativas. Aprender é organizar o mundo, realidade complexa e desbordante de dados, segundo a própria perspectiva. Porém, a organização posta ou apresentada ao aprendente demanda a chancela da significação (MAYER, 2002).

$\mathrm{O}$ processo de aprendizagem baseia-se no desenvolvimento consciente de capacidades que viabilizam esse sentido e organização (capacidade de conceituar, contextualizar, nomear, comparar, estabelecer ligações e sinergias, dentre outras) (RUIZ, 2006).

Dessa discussão depreende-se a complexidade da relação aluno - professor, que é naturalmente influenciada por fatores de natureza cultural, social, política, técnica, científica, afetiva e emocional. Os papéis desempenhados por esses atores extrapolam o ambiente de sala de aula, alcançando diferentes células ou núcleos sociais (MAYER, 2002; RUIZ, 2006).

As disciplinas se organizam em torno de conceitos hierarquicamente estruturados. $\mathrm{O}$ papel do professor é apresentar ao discente essa organização transitoriamente estabelecida, mediando a experiência de aprender. Essa assertiva mostra-se coerente, tendo em vista que,

(...) a estrutura mental de um estudante dificilmente reúne os elementos conceituais e atitudinais que o permitem descobrir e redescobrir um princípio ou lei de forma autônoma, o que, portanto, requer orientação metodológica do estudante para alcançar a meta de aprendizagem proposta. (LÓPEZ, p.5, 2009).

Destituída pela primazia da realidade acadêmica, o paradigma condutivista que supervalorizava e isolava o professor, foi gradativamente desconstruído, dando azo a construção da aprendizagem, em lugar da acrítica condução. O pensar construtivista é tripolar por natureza, compreendendo o sujeito aprendente, seus pares e objeto (ORELLANA, 2009).

A formação universitária é fecunda em movimentos de construção e desconstrução de conceitos, movidos pela ampliação das capacidades de pensar, problematizar, argumentar e organizar a realidade (RUIZ, 2006).

Desse entendimento decorre que, a aprendizagem caracteriza-se pela autonomia seletiva. Implica afirmar que, ao sujeito aprendente cabe manter ou desconstruir a aludida organização conceitual, orientado pela significação atribuída. Assim, a definição do itinerário de aprendizagem constitui escolha do aluno (consciente ou não) (POZO, 1989; RESNICK, COLLINS, 1996).

Agente fundamental no processo ensino-aprendizagem, o discente explora e articula de modo espontâneo os conhecimentos e concepções preexistentes, intuições, experiências anteriores, associações, interesses e expectativas, atribuindo um significado particular ao objeto de aprendizagem. (VASCONCELOS, p. 4, 2015).

Repertório inicial, a estrutura cognitiva do indivíduo é composta por saberes, conceitos, vivências e impressões, configurando a janela pela qual o aprendente apreende os 
Revista Ambiente Contábil - ISSN 2176-9036 - UFRN - Natal-RN. v. 9. n. 1, p. 117 - 143, jan./jun. 2017.

dados da realidade e interpreta o mundo (CICUTO, CORREIA, 2013; SCHLEMMER, SIMÃO NETO, 2008; SAXE, MURILLO, 2011; CASTAÑEDA, 2006; RODRÍGUEZ, 2004).

Essa bagagem cognitiva, associada ao compromisso emocional do aprendente, sua predisposição, interesse e motivação, influenciam naturalmente o desempenho do aluno (LABATUT, 2000; BENGOECHEA, 2003; CASTAÑO, CALLES, 2000; KLIMENKO, ALVARES, 2009; PÉREZ, 2013; VIDAL-ABARCA, 2000).

Ausubel define estrutura cognitiva como uma construção hipotética dotada de uma organicidade determinante de atitudes e comportamentos. São organizações claras e estáveis conectadas a um conhecimento. Eventuais conflitos entre o novo conhecimento e essa estrutura de base inviabiliza qualquer conexão. Implica afirmar que a estrutura cognitiva é um elemento fundamental na aquisição e retenção de conhecimento (ROMAN, 2005).

Aprender de modo significativo é fazê-lo guiado pela relevância do conteúdo (filtro seletivo). Assim, compreende essencialmente a negociação de sentidos, ampliação e reconfiguração de ideias, se já integradas à estrutura mental do sujeito aprendente (VASCONCELOS, 2015; MOREIRA, 2003; MÉNDEZ, 1993).

Numa acepção pragmática, "A aprendizagem significativa é um processo segundo o qual se relaciona um novo conhecimento ou uma nova informação com a estrutura cognitiva da pessoa que aprende de forma não arbitrária e substantiva ou não literal." (PALMERO, p. 11, 2010).

A interação entre os novos conhecimentos ou conceitos e aqueles preexistentes não alcança uma totalidade porque o sujeito considera apenas aspectos relevantes. Esse movimento de inclusão denomina-se ancoragem. Os conceitos de referência, amplos e complexos, são chamados de inclusivos (ideias-âncoras) e seu corpus, de subsunções (VASCONCELOS, 2015; PALMERO, 2010).

Desse movimento, de conversão do significado lógico ou potencial em significado cognitivo, resultam estruturas cognitivas progressivamente diferenciadas, claras e estáveis. Idiossincrática por natureza, a significação assegura a funcionalidade dos novos conhecimentos. Por essa razão, a elaboração dos conceitos compreende as etapas de filtragem, escolha, decodificação e ressignificação da informação assimilada do meio, definindo o itnerário que estrutura o novo conhecimento (VASCONCELOS, PRAIA, ALMEIDA, 2003).

Por essa lente, a aprendizagem significativa se impõe como processo e ao mesmo tempo, produto. Palmero (2010) argumenta que

A atribuição de significado à nova informação é resultado emergente da interação entre subsumidores claros, estáveis e relevantes presentes na estrutura cognitiva e essa nova informação ou conteúdo. Como consequência disso, essas subsumidores ou ideias-âncoras, poderosos e explicativos, servem como base para futuros aprendizados (PALMERO, p. 12, 2010).

A aprendizagem significativa se assenta no entendimento de que o aprendizado profundo se processa por meio de relações diversas entre observações, experiências atuais e conhecimentos prévios (MARTÍNEZ, DEL MORAL PÉREZ, 2010; ARENAS, 2005; VASCONCELOS, 2015). Com efeito,

(...) a aprendizagem constituída e significativa permite a construção / desconstrução / reconstrução de esquemas que tecem redes de significados: a ação do professor deve incidir na atividade construtiva do aluno, criando condições favoráveis para que os esquemas de conhecimento sejam os mais profícuos possíveis (D’ÁVILA, p. 94, 2006).

Assim, uma vez baseada em intraconexões, essa aprendizagem mobiliza o aparato cognitivo na construção de novos conhecimentos em um movimento silencioso de atualização, patrocinando o amadurecimento do aprendente. Entretanto, 
Revista Ambiente Contábil - ISSN 2176-9036 - UFRN - Natal-RN. v. 9. n. 1, p. 117 - 143, jan./jun. 2017.

Para modificação e enriquecimento progressivo dos esquemas de conhecimento, é preciso que o professor seja capaz de gerar o conflito e sua possibilidade de resolução, sendo também capaz de gerar a confrontação dos pontos de vista divergentes na sala de aula (transformar os conflitos em controvérsias) e, finalmente, compreender os erros e resultados obtidos como pontos de partida para a modificação dos esquemas de conhecimento (D’ÁVILA, p.94, 2006).

Nessa perspectiva de pensamento,

Aprender é construir estruturas de assimilação. Estruturas que se tornam progressivamente capazes de, sem negar o biológico, assimilar a extraordinária diversidade e complexidade da produção cultural humana e dar respostas cada vez mais adequadas a essa produção e, no limite, produzir novidades no âmbito dessa cultura (DONGO-MONTOYA, p.13, 2009).

A assimilação representa a etapa de captura e integração de dados da realidade à estrutura existente, seguida da classificação desses dados (perceptuais, motores ou conceituais). A acomodação consiste no movimento efetivo de organização, ajuste e se for o caso, de modificação da estrutura. A equilibração é a estabilidade (provisória) dessa estrutura, após as integrações realizadas (VASCONCELOS, 2015).

Por essa senda, a predisposição do indivíduo para aprender, o reconhecimento da relevância dos conteúdos desenvolvidos e sua repercussão para formação e vida cotidiana, potenciam sua capacidade de assimilação e integração efetiva à estrutura cognitiva; quadro que torna esses movimentos não mecânicos, ou nem mesmo arbitrários, mas sim lógicos, intradialógicos e consistentes. A decisão de aprender reclama intencionalidade (ROMAN, 2005).

A aprendizagem significativa é um fenômeno complexo que demanda intensa mobilização das estruturas neurais visando interpretar a realidade, estabelecer relações, construir argumentos, realizar inferências e elaborar padrões. Nesse sentido, o conhecimento do aprendente constitui um fator determinante da aprendizagem, tendo em vista que representa a base cognitiva que recepciona os novos conhecimentos dando significado à experiência de aprender. Mobilizar, ativar, relacionar, revisar e modificar são ações típicas do fenômeno de aprendizagem. Conhecer significa compreender o significado e ressignificar implica fazer escolhas (MAYER, 2002; ESCORIZA NIETO, 1998; ROMAN, 2005).

Depreende-se então, que o sujeito, o significado e valor atribuído aos conteúdos, constituem o cerne do conceito de aprendizagem significativa (ROMAN, 2005).

A teoria da aprendizagem significativa proposta por David Ausubel (AUSUBEL, 1963) aponta uma nítida distinção entre a aprendizagem por memorização, na qual o aluno não consegue relacionar e integrar estavelmente novos conceitos e proposições, e a aprendizagem significativa, pela qual o aluno integra ativamente novos conhecimentos àqueles relevantes anteriormente assimilados.

$\mathrm{Na}$ aprendizagem mecânica ou baseada em memorização, o conhecimento é tratado como um produto acabado recebido passivamente, despertado por alguma necessidade. Inexistem interações estáveis e consistentes entre os novos conceitos e aqueles integrantes da estrutura cognitiva. As aquisições se dão de modo arbitrário, sem qualquer ancoragem, resultado tão somente de práticas de adestramento e repetição desatadas de qualquer iniciativa de criticidade (SILVA, PEREZ, 2012; PEREIRA, 2007; POZO, 1989).

Aprender por essa via implica tão somente apreender informações transitoriamente na memória operacional (de curto prazo), por essa razão a retenção não é estável. A incorporação à memória de longo prazo depende do acolhimento desta pela estrutura cognitiva do aprendente, tal como se fossem peças de um quebra-cabeça. Nesse processo de internalização, a repetição e a reflexão têm papel fundamental, especialmente porque a ação de refletir tem 
como consequência promover pontes e encadeamentos no âmbito dessa estrutura. Destaque-se que a estrutura cognitiva tem natureza conceitual (ROMAN, 2005).

Ressalte-se, porém que, essa forma de aprender não se opera em um vácuo cognitivo, pois não se verifica a ausência total de conexões. O que ocorre é que as poucas associações não são consistentes o suficiente para engendrar a significação. Essa característica, entretanto, não desprestigia o formato, uma vez que na exploração inicial de realidades a aprendizagem memorística é pode tornar-se um gatilho espontâneo necessário (AUSUBEL, 1963; SILVA, PEREZ, 2012; RIBEIRO, 2003).

Embora não se tenha enfatizado, existem tipos intermediários de aprendizagem, não tratados nesse trabalho por fugirem ao seu escopo.

A teoria formulada por Ausubel lança reflexões acerca das condições, mecanismos e propriedades da aprendizagem; igualmente, sobre as estratégias eficazes para ensejar trocas deliberadas com o ambiente, na construção de significados nos planos individual e social.

Nesse intento, aponta condições ideais ao processo:

- o empreendimento de atitudes potencialmente significativas, definindo um status de predisposição à aprendizagem (componente emocional e afetivo);

- a apresentação de um material didático potencialmente significativo, o que reclama na maioria dos casos a articulação de saberes locais e a exploraçãoo de interesses e desejos;

- a existencia de ideias-âncoras ou subsunções, o que na linguagem curricular se denomina de pré-requisitos;

- uma apresentação lógica e contextualizada de conceitos;

- um desenho instrucional criativo e instigante.

Assim, segundo Ausubel (1968, apud NOVAK e CAÑAS, 2008), caso fosse necessário reduzir toda a psicologia educacional a apenas uma assertiva definidora, essa se traduziria pela expressão "o que o aprendiz já sabe", que para ele é o fator de influência mais importante e configurante da aprendizagem. Entretanto, ampliando esse sentido, o processo de a aprendizagem significativa implica reflexão sobre os componentes indutores da formação de saberes: quem é o aluno? (componente identitário)? O que o aluno deseja? (componente volitivo e de autodeterminação) O que o aluno sente, vê e percebe (componente emocional)? Do que o aluno gosta? (componente afetivo) Que bagagem traz? (componente históricosocial) Onde deseja estar? Por que? (componente de significação).

Ao comparar o conhecimento novo com aquele prévio (esquema cognitivo preexistente), o sujeito aprendente promove uma leitura de confronto e ressignificação, que pode culminar em sua reformulação e consequente atualização, ou na mera confirmação, traduzindo um esforço espontâneo de contextualização da realidade (figura 1)

Figura 1 - Ciclo da aprendizagem significativa

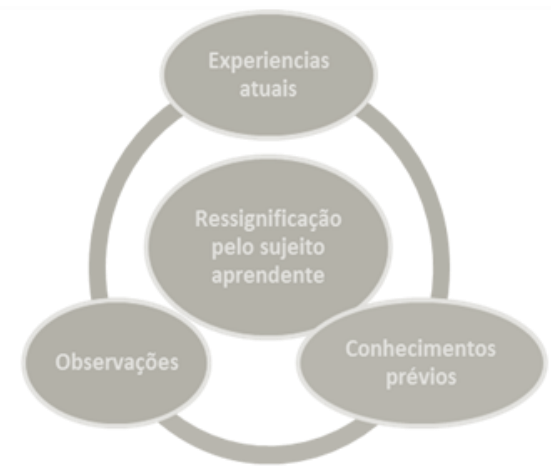

Fonte: Elaborado pelos autores. 
Revista Ambiente Contábil - ISSN 2176-9036 - UFRN - Natal-RN. v. 9. n. 1, p. 117 - 143, jan./jun. 2017.

Esse mecanismo situa a aprendizagem como processo dinâmico, onde a estrutura cognitiva renova-se continuamente, alimentada pela aproximação entre conteúdo e realidade. Quanto melhor esse enquadramento e proximidade, tanto menores serão os esforços de mediação verbal (SILVA et al, 2015; VICTER, 2015; VASCONCELOS, 2015).

Ante essas exposições, percebe-se que a teoria significativa valoriza a experiência da "descoberta" do conhecimento já assimilado e internalizado pelo aprendiz. Apesar da logicidade, à época (década de 1960) essa perspectiva (intrasujeito) desafiou o pensamento comportamentalista (behaviorista), que enfatizava essencialmente a influência de variáveis externas sobre o fenomeno da aprendizagem (FAIRSTEIN, GYSSELS, 2005).

O comportamentalismo deu vazão à histórica modelização do aprendente, desconsiderando-o como um processador nato de informações (PEREIRA, 2007).

Já o cognitivismo, nascedouro da teoria de aprendizagem significativa, expandiu os olhares de pesquisadores e psicólogos enfatizando o processo de cognição em lugar do produto. O comportamento, nessa concepção, se qualifica como produto, onde aluno e professor são meramente agentes mediadores da aprendizagem e não um elemento passivo e dependente de estímulos exteriores. De fato, o comportamento constitui tão somente a evidência visível da aprendizagem. A estrutura cognitiva (não visível) é a base que o alicerça. Com mais de 40 anos de História, a teoria explica como se efetiva e é facilitada a cognição humana (PALMERO, 2000; PERRAUDEAU, 2009).

Por essa lente, o processo cognitivo pressupõe relações entre variáveis externas (estratégias de ensino-aprendizagem, conhecimentos e manipulações instrucionais) e internas (o fenômeno de aprendizagem em si e as características do aprendente). (MAYER, 2002)

Em nível geral, a pesquisa de Ausubel é contributiva porque revela como, por quais meios e porque o indivíduo aprende ou não aprende em situações formais, incorporando em seu escopo aspectos relacionados aos estilos cognitivos, memória, conteúdo programático, atribuição e transferência de significado, organização e qualidade do material didáticopedagógico (RESNICK, 1996).

Alicerçada nos pilares teóricos da Psicologia, a teoria da aprendizagem significativa norteia o empreendimento de diferentes estratégias e emprego de 'meios' pelo discente para administrar os próprios processos de aprendizagem. Dentre essas estratégias, enquadram-se aquelas baseadas em organizadores gráficos, em especial o mapeamento conceitual, objeto dessa pesquisa.

\subsection{MAPAS CONCEITUAIS}

\subsubsection{CONCEITO E CARACTERIZAÇÃO}

Os mapas conceituais representam graficamente a estrutura e movimentos decorrentes da aprendizagem significativa. Segundo o modelo idealizado por Novak e Gowin (1988), essas representações, como o próprio nome sugere, compõem-se por conceitos, proposições, palavras e expressões de ligação. O conceito corresponde ao conteúdo de aprendizagem, alvo de abstração e exploração de significados.

Esses schemas expressam as representações discursivas enunciadas pelo aprendente, traduzindo os modelos mentais elaborados pelo indivíduo com base nas interações sociais e aprendizagens, acessando o território íntimo de suas crenças subjetivas e valores (BITTENCOURT, 2006; ORELLANA, 2009; VASCONCELOS, 2015).

Os mapas conceituais diferem de outros organizadores gráficos, a exemplo do quadro sinóptico porque enquanto o primeiro viabiliza a construção de relações e hierarquias entre objetos, dentro e fora do escopo da aula, o segundo ilustra tão somente a organização interna do tema apresentado. De fato, o quadro sinóptico, técnica antiga e amplamente empregada, 
tem alcance restrito tendo em vista que consiste tão somente em conceitos dispostos verticalmente (ARENAS, 2005).

Os mapas de conceito apresentam a organicidade da construção do conceito, o que amplia as possibilidades de aplicação pedagógica, seja como estratégia de ensinoaprendizagem, de pesquisa, instrumento diagnóstico ou meramente de aprendizagem (VASCONCELOS, 2015; SHITSUKA, SILVEIRA, SHITSUKA, 2011; LESSA, PINTO, 2001; CARABETTA JÚNIOR, 2013).

Esses mapas diferem dos mapas mentais em diferentes aspectos. Os mapas mentais podem incluir códigos distintos a exemplo de imagens e links, em cores e fontes distintas, mas sem palavras de ligação. Essa característica confere ao instrumento originalidade e estética peculiar. Por essa razão, os mapas conceituais são mais 'didáticos' do que os mentais, o que potencializa sua inclusão na composição de estratégias de ensino (MARQUES, 2008; SHITSUKA, SILVEIRA, SHITSUKA, 2011; LESSA, PINTO, 2001).

\subsubsection{ASPECTOS GERAIS DA ELABORAÇÃO E 'DESENHOS'}

Arenas (2005) destaca como etapas principais de elaboração de mapas conceituais: a escolha do conceito a ser desenvolvido, à luz da proposta curricular e objetivos de aprendizagem; a identificação dos conceitos relacionados àquele principal; o estabelecimento de relações ou pontes entre os conceitos (hierarquias, sequência, sentido e direção); a definição das palavras ou expressões de ligação apropriadas para integrar os conceitos (podem ser verbos, locuções, preposições); a concretização das vinculações (associações), respeitando a lógica subjacente ao relacionamento e o teor da mensagem comunicada.

Os mapas são avaliados segundo os parâmetros de validade, clareza, veracidade das relações, consistência, coerência e unidade. Seu formato ou estrutura das representações gráficas denunciam como o conceito foi construído, revelando aspectos como logicidade, inter ou transdisciplinaridade, complexidade e profundidade, do que resulta a diversidade de modelos: lineares, hierárquicos, reticulares ou em rede, dentre outros. (VEIGA, 2013; ARENAS, 2005; CAÑAS, 2000; NOVAK, 1988)

Quando os elementos estão organizados hierarquicamente, em geral, apresentam estrutura verticalizada (figura 2).

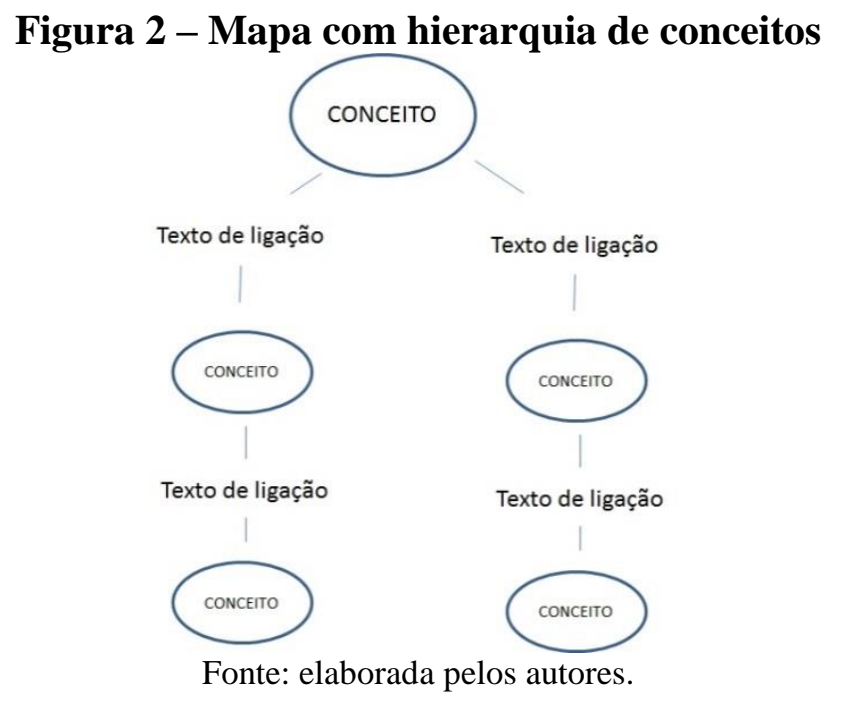

Nesses casos, no topo dos mapas são posicionados os conceitos principais ou 'guardachuva' (aqueles que englobam, acolhem, comportam outros conceitos) e na base, os conceitos englobados ou pré-requisitos (figura 3). 
Revista Ambiente Contábil - ISSN 2176-9036 - UFRN - Natal-RN. v. 9. n. 1, p. 117 - 143, jan./jun. 2017.

Os mapas de estrutura arbórea têm origem em um ou mais conceitos-raiz, os quais se desdobram em outros.

Figura 3 - Mapa de estrutura arbórea

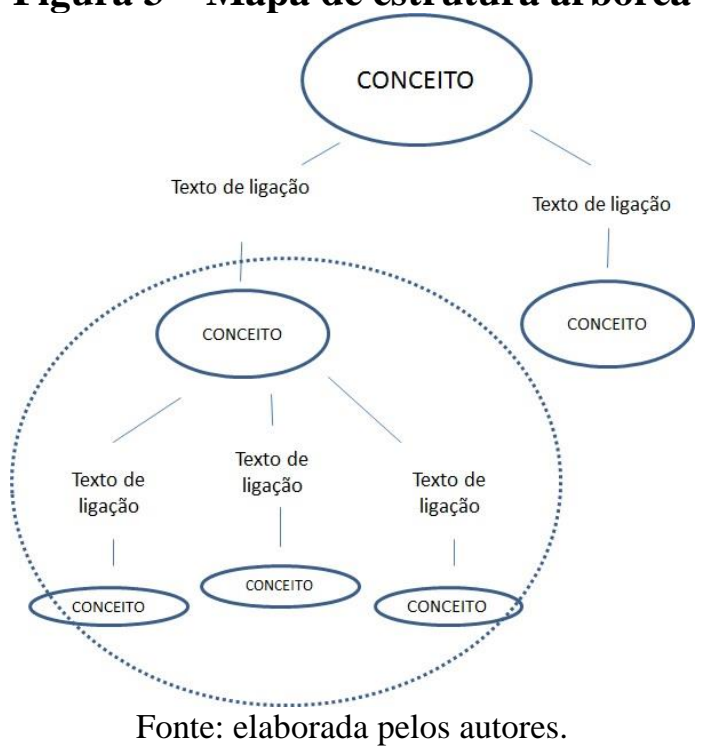

Os mapas conceituais multidirencionais ou sistêmicos são recomendados quando se opera conceitos complexos e interdisciplinares, cujos elementos se imbricam em diferentes sentidos e direções. Em geral, apresentam diferentes polos e estrutura de encadeamentos nucleares, como ilustrado na figura 4.

Figura 4 - Mapas de estrutura multidimensional

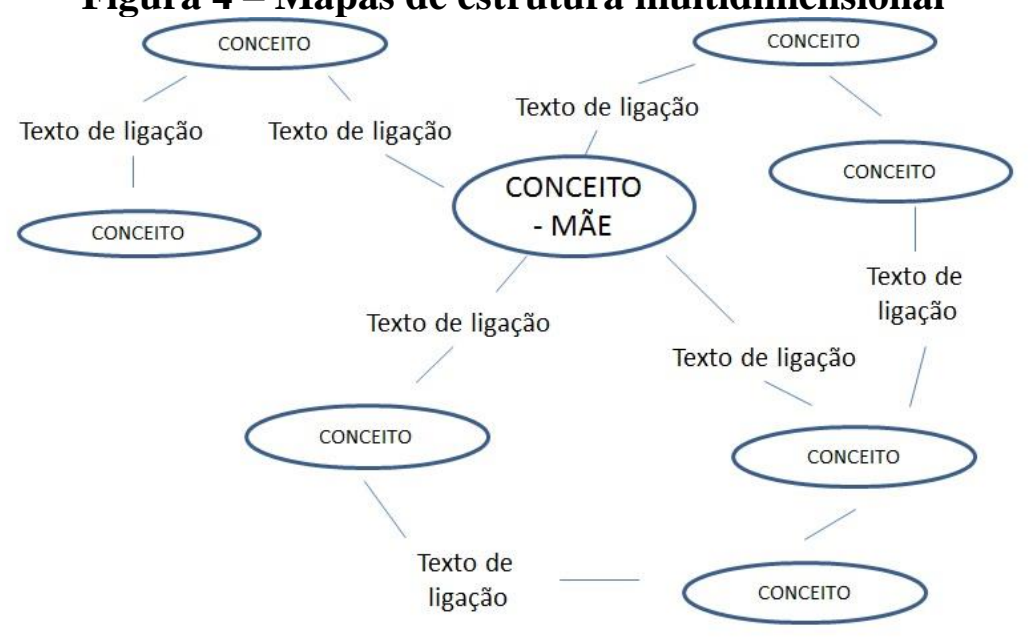

Fonte: elaborada pelos autores. (figura 5)

Os conceitos presentes em cada nó são 'irradiantes', interconectados ou não entre si 
Figura 5 - Representações da realidade

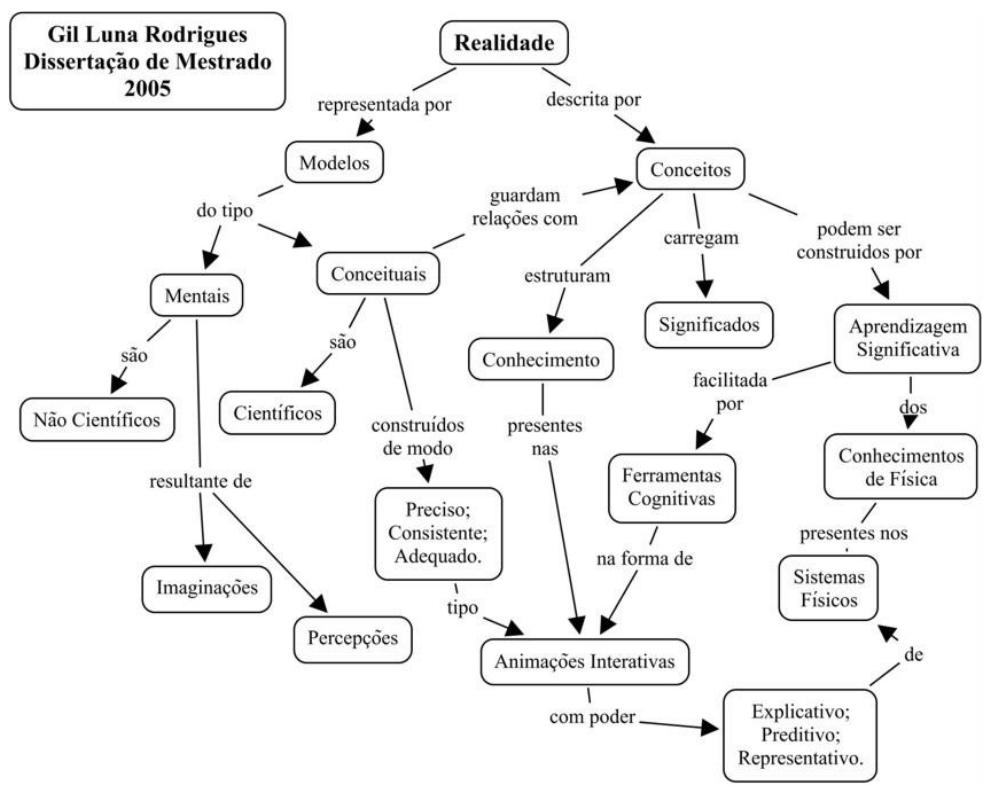

Fonte: Tavares (2007, p. 82) - adaptado.

A escolha da tipologia adequada depende da complexidade do conceito, variáveis articuladas em sua construção, sentido e direção, bem como do grau de encadeamento dos elementos ou fatores analisados. Assim, refletem diferentes arranjos conceituais ou representações.

Os mapas com formato de teia de aranha, exemplo ilustrado na figura 6, mostram-se mais adequados quando o conceito elaborado enseja delimitações, enfoques, desdobramentos ou recortes distintos, todavia, sem a necessidade de hierarquizar ou transversalizar os elementos conceituais (TAVARES, 2007).

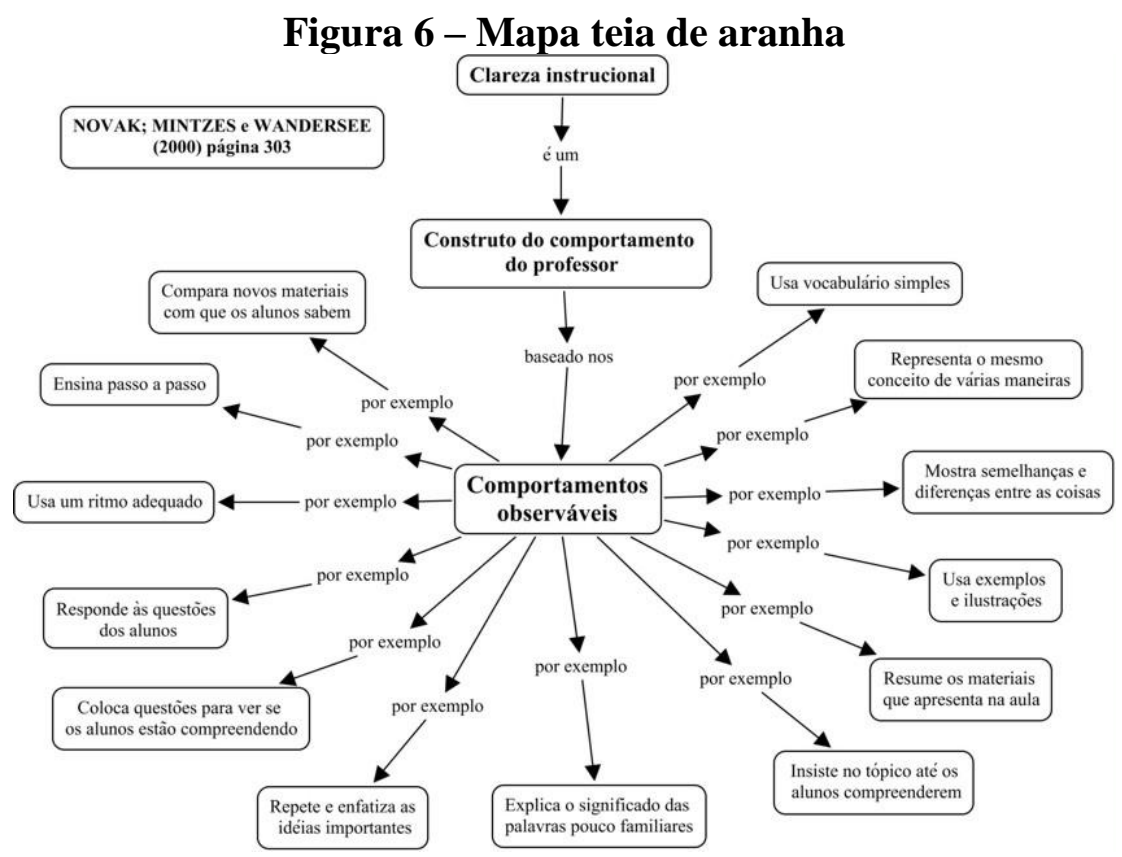

Fonte: Tavares (2007, p. 76). 
Revista Ambiente Contábil - ISSN 2176-9036 - UFRN - Natal-RN. v. 9. n. 1, p. 117 - 143, jan./jun. 2017.

O quadro1 resume as características, vantagens e restrição da aplicação das estruturas correspondentes.

\section{Quadro 1 - Estrutura dos mapas conceituais}

\begin{tabular}{|c|c|c|c|}
\hline Estrutura & Características & Vantagens & Restrições \\
\hline $\begin{array}{l}\text { Estrutura teia de } \\
\text { aranha }\end{array}$ & $\begin{array}{l}\text { Organização nuclear, onde } \\
\text { o conceito-mãe (gerador) se } \\
\text { posiciona no centro do } \\
\text { mapa. } \\
\text { Os demais conceitos se } \\
\text { arranjam ou irradiam em } \\
\text { torno desse núcleo. }\end{array}$ & $\begin{array}{l}\text { A irradiação de relações } \\
\text { conceituais dá conta de } \\
\text { situações e contextos } \\
\text { complexos, todavia sem } \\
\text { enfatizar relações } \\
\text { hierárquicas, ou mesmo } \\
\text { transversais. }\end{array}$ & $\begin{array}{l}\text { A ausência de hierarquia, } \\
\text { aliada à estrutura de } \\
\text { ramificação dos núcleos } \\
\text { conceituais podem } \\
\text { comprometer sua } \\
\text { compreensão. }\end{array}$ \\
\hline $\begin{array}{l}\text { Estrutura } \\
\text { hierárquica }\end{array}$ & $\begin{array}{l}\text { Organização baseada na } \\
\text { lógica da inclusão, partindo } \\
\text { de um conceito-mãe } \\
\text { (guarda-chuva) em direção } \\
\text { aos desdobramentos } \\
\text { conceituais que compõem } \\
\text { sua definição. }\end{array}$ & $\begin{array}{l}\text { São mapas mais ‘didáticos’ } \\
\text { porque têm como ponto de } \\
\text { partida, conceitos mais } \\
\text { abrangentes (inclusivos), } \\
\text { acomodando aqueles } \\
\text { necessários à sua } \\
\text { compreensão. } \\
\text { A subsunção se dá de } \\
\text { maneira muito clara. }\end{array}$ & $\begin{array}{l}\text { Pode não dá conta de } \\
\text { situações ou conceitos } \\
\text { complexos, especialmente } \\
\text { quando sua composição } \\
\text { reclama links } \\
\text { interdisciplinares. }\end{array}$ \\
\hline $\begin{array}{c}\text { Estrutura } \\
\text { multidimensional }\end{array}$ & $\begin{array}{l}\text { Estrutura multinucleada e } \\
\text { encadeada. } \\
\text { Existência de diferentes } \\
\text { núcleos conceituais, } \\
\text { imbricados entre si. }\end{array}$ & $\begin{array}{l}\text { Esses mapas dão conta de } \\
\text { situações complexas. }\end{array}$ & $\begin{array}{c}\text { Sua estrutura aberta e } \\
\text { encadeada pode dificultar } \\
\text { sua compreensão, } \\
\text { denunciando maturidade de } \\
\text { seu autor. }\end{array}$ \\
\hline
\end{tabular}

Fonte: elaborado pelos autores inspirado em Tavares (2007).

Independente da estrutura adotada, segundo Novak e Cañas (2008), o processo de construção dos mapas conceituais demanda, além do domínio na área de conhecimento, que o elaborador mantenha a mente aberta ao diálogo interdisciplinar, sem prejuízo da clareza e coerência das relações conceituais.

\subsubsection{APLICAÇÃO: VANTAGENS E RESTRIÇÕES}

A revisão de literatura empreendida aponta diferentes vantagens para a aplicação da técnica de mapeamento conceitual:

- o resgate e mobilização, na interpretação dos conteúdos escolares, de conhecimentos prévios, experiências, contiguidades, semelhanças, hierarquia de valores, contradições e dados da realidade do aluno (CAÑAS, 2000; VEIGA, 2013; PEÑA, 1994);

- o favorecimento da memorização, simplificação e síntese (ARENAS, 2005; VASCONCELOS, 2015);

- a oportunidade do sequenciamento da informação, auxiliando o indivíduo na hierarquização de conceitos e na identificação de pré-requisitos; (ARENAS, 2005; NOVAK, GOWIN, 1988)

- a sedimentação dos conceitos-chave desenvolvidos em aula, especialmente aqueles apropriados de outras áreas do conhecimento (GAVA, MENEZES, CURY, 2003; ARENAS, 2005; VASCONCELOS, 2015);

- o auxílio na organização dos elementos que compõem o conceito ou integram o raciocínio subjacente à solução de problemas (VEIGA, 2013; NOVAK, GOWIN, 1988; MOREIRA, 2007); 
Revista Ambiente Contábil - ISSN 2176-9036 - UFRN - Natal-RN. v. 9. n. 1, p. 117 - 143, jan./jun. 2017.

- uma maior compreensão do docente acerca de como o aluno percebe, interpreta, relaciona e valoriza os conteúdos desenvolvidos ao longo da aula, possibilitando intervenções mais objetivas e eficazes na reorganização desse conteúdo (VEIGA, 2013; ARENAS, 2005; CAÑAS,2000; NOVAK, 1988; MOREIRA, 2007);

- a aproximação do professor da estrutura cognitiva do sujeito aprendente (VEIGA, 2013; MOREIRA, 2007);

- o incentivo à autogestão do conhecimento (prévio ou emergente); (VEIGA, 2013; VASCONCELOS, 2015; ROMAN, 2005);

- a identificação de fragilidades conceituais, ensejando o encaminhamento dos ajustes metodológicos necessários (ARENAS, 2005; VEIGA, 2013);

- a operação de conceitos complexos por meio do manejo de imagens e estruturas mentais, ensejando uma síntese adequada (ARENAS, 2005);

- a conexão saberes interdisciplinares (VASCONCELOS, 2015).

$\mathrm{O}$ uso de mapas conceituais também mune o educador de um instrumento de verificação do desempenho acadêmico, pois refletem o processo de significação, sendo influenciados pelas necessidades do aprendente, seus desejos, tensões e aspirações (ROMAN, 2005).

Como o campo epistemológico da área define e orienta a formulação dos critérios de avaliação, admitindo-se seu uso como recurso para obtenção de diagnóstico, recomenda-se que sejam observados nos mapas parâmetros técnicos e atitudinais, a exemplo da: lógica operante, organicidade, profundidade, alcance das relações estabelecidas, significado atribuído, transparência e conexões interdisciplinares (VASCONCELOS, 2015; ROMAN, 2005; VEIGA, 2013).

O emprego da técnica no processo de avaliação possui função amplamente diagnóstica e proativa, potencializando as possibilidades de intervenção docente com vistas a facilitar a aprendizagem dos alunos. Em movimento de convergência a esse ponto de vista, Veiga (2013) reforça:

Os mapas conceituais são excelentes instrumentos de avaliação por sua capacidade de evidenciar a individualidade da aprendizagem, o estado do conhecimento representado pelos alunos, bem como de detectar fragilidades dos aprendizes (VEIGA, 2013, p. 54).

A aplicação de mapas conceituais situa o professor relativamente ao conhecimento elaborado pelo aluno: sua capacidade de organização, projeção da realidade, contextualização, profundidade de abordagem, filtro individual de relevância e interdisciplinaridade (ARENAS, 2005; CAÑAS, 2000; NOVAK, 1988).

Quando elaborado conjuntamente, a técnica enseja a discussão coletiva de situações, problemas ou provocações, desenvolvendo habilidades de comunicação, integração e negociação (VEIGA, 2013).

Arena (2005) destaca que os mapas conceituais:

-diagnosticam a estrutura cognitiva dos estudantes depois de uma exposição ou leitura de um material.

-facilitam o desenvolvimento do vocabulário do estudante.

- melhoram a discussão em grupo de um conteúdo ou domínio específico.

- favorecem a aprendizagem de textos tradicionais.

- facilitam a integração da informação obtida de diferentes fontes.

- melhoram a esquematização de conteúdos.

- ajudam a representação de problemas.

(...)

- fornecem uma forma eficaz de identificar as ideias fundamentais e relações entre conceitos de diferentes níveis de complexidade. 
-conduzem à formação de imagens mentais que podem ser utilizados posteriormente para guiar a memorização de proposições verbais.

- ajudam a compensar deficiências de desenvolvimento das habilidades

verbais dos alunos (ARENA, 2005, p. 10).

$\mathrm{O}$ valor pedagógico da técnica, entretanto, reclama problematização, autonomia e incentivo à participação do aluno, o que confere ao professor as funções de mediador e facilitador, promovendo intervenções visando a retroalimentação corretiva.

A técnica de mapeamento condiciona aluno e professor ao estabelecimento de nexos ou vínculos do conteúdo estudado com outros elementos (consequências, aplicações, composição), extrapolando os limites do próprio currículo. Igualmente, afasta o foco clássico na memorização, priorizando o raciocínio, o que é coerente porque o aluno esquematiza mentalmente sua trilha de raciocínio. Por esse olhar, a improvisação desconexa cede lugar ao planejamento e estruturação metódica (SHITSUKA, SILVEIRA, SHITSUKA, 2011; LESSA, PINTO, 2001; CARABETTA JÚNIOR, 2013).

A elaboração do conhecimento parte do conceito em direção às implicações, definições e repercussão.

A qualidade dos mapas conceituais é influenciada pelas circunstancias de sua aplicação, tempo disponível, clareza conceitual, condições do ambiente, conexões que o tema comporta e capacidade de concentração.

O perfil do sujeito aprendente é determinante para efetividade da aprendizagem significativa por meio do aporte de mapas conceituais.

Cada aluno é singular no que diz respeito a conhecimentos prévios, estruturas cognitivas, bem como a habilidades visoespaciais. O estilo de aprendizagem, inteligência dominante e contexto cultural também influenciam o desempenho (ARENA, 2005).

A sinergia dos fatores citados afeta a concatenação das informações ilustradas nos diagramas (na configuração do mapa conceitual) potencializando seu emprego em iniciativas pedagógicas distintas.

\section{MATERIAIS E MÉTODOS}

\subsection{ENQUADRAMENTO DA PESQUISA}

Essa pesquisa enquadra-se, quanto a natureza dos dados, como qualitativa em razão da natureza dos dados investigados: relatos de experiências.

As pesquisas qualitativas objetivam, geralmente, explicar, descrever e explorar fenômenos sociais, ensejando seu entendimento. Nesse intento, investigam perfis, práticas, relatos, experiências individuais ou de grupos, histórias biográficas, modus de interação e documentos (imagens, textos, filmes, músicas), respeitando o contexto natural dos fenômenos estudados (GUERRA, 2006; GOLDENBERG, 1997; STRAUSS; CORBIN, 2008; TOZONIREIS, 2009; DENZIN, LINCOLN, 2000; FLICK, 2009).

Estudos qualitativos trazem à superfície a maneira como as pessoas percebem e atribuem significado à realidade (na situação em tela, a técnica de mapeamento conceitual), explorando intensivamente a natureza dos fenômenos. A questão problematizante proposta e objetivos se alinham e harmonizam nessa direção.

"Pesquisas na abordagem qualitativa se caracterizam, principalmente, por estudar subjetividades, crenças, valores, representações da realidade, opiniões, enfim, fenômenos intrinsecamente complexos." (FAGUNDES, 2009, p. 21). De fato, aos objetivos desses estudos "[...] interessa muito mais compreender e interpretar seus conteúdos que descrevêlos" (TOZONI-REIS, 2009, p.15). 
Quanto aos objetivos, o estudo qualifica-se como exploratório, refletindo o estágio embrionário da pesquisa.

Para consecução desses propósitos, optou-se pela pesquisa-ação, método de investigação composto pelas seguintes etapas: planejamento, implementação de uma ação, descrição e avaliação de reação visando melhorar determinada prática.

A pesquisa-ação caracteriza-se pela intervenção na realidade objeto de investigação, prestigiando a participação interativa dos sujeitos da pesquisa na construção de um feedback (THIOLLENT, 2011; TRIPP, 2005; FRANCO, 2005).

\subsection{PROCEDIMENTOS METODOLÓGICOS}

A técnica de mapeamento foi aplicada em duas turmas, em disciplinas distintas da área contábil: ANÁLISE DE BALANÇOS e ANÁLISE DE CUSTOS. A escolha de aplicação foi motivada pela natureza das disciplinas, de enfoque menos normativo ou prescritivo.

As disciplinas contábeis possuem notada carga prescritiva, exceção daquelas que se orientam para análises gerenciais e processo decisório, acenando para uma maior plasticidade e criatividade das práticas pedagógicas.

Participaram da experiência didático-pedagógica 48 alunos, distribuídos como segue:

\begin{tabular}{|c|c|}
\hline DISCIPLINAS & NÚMERO DE PARTICIPANTES \\
\hline Análise de balanços & 28 \\
\hline Análise de custos & 20 \\
\hline
\end{tabular}

\section{a) APLICAÇÃO NA DISCIPLINA DE ANÁLISE DE BALANÇOS}

Desenvolveu-se na aula expositiva o tema 'CAPITAL DE GIRO: conceito, composição e aspectos gerenciais'. Os slides consistiram basicamente em mapas conceituais, visando a preparação do aluno para aspectos técnicos de sua elaboração. Em sua construção, utilizou-se o software Cmaptools.

Após exposição, foram transmitidas orientações acerca da técnica de elaboração de mapas conceituais, sedimentando as impressões transmitidas ao longo da exposição de conteúdo. Findado esse momento, a cada aluno foi solicitado o preparo de um mapa conceitual destacando a IMPORTÂNCIA ATRIBUÍDA À ADMINISTRAÇÃO DO CAPITAL DE GIRO PARA AS ORGANIZAÇÕES, relacionando livremente conceitos anteriormente assimilados, proposições, opiniões e experiências.

A figura 7 ilustra os procedimentos adotados.

Figura 7 - Mapa conceitual como instrumento de avaliação

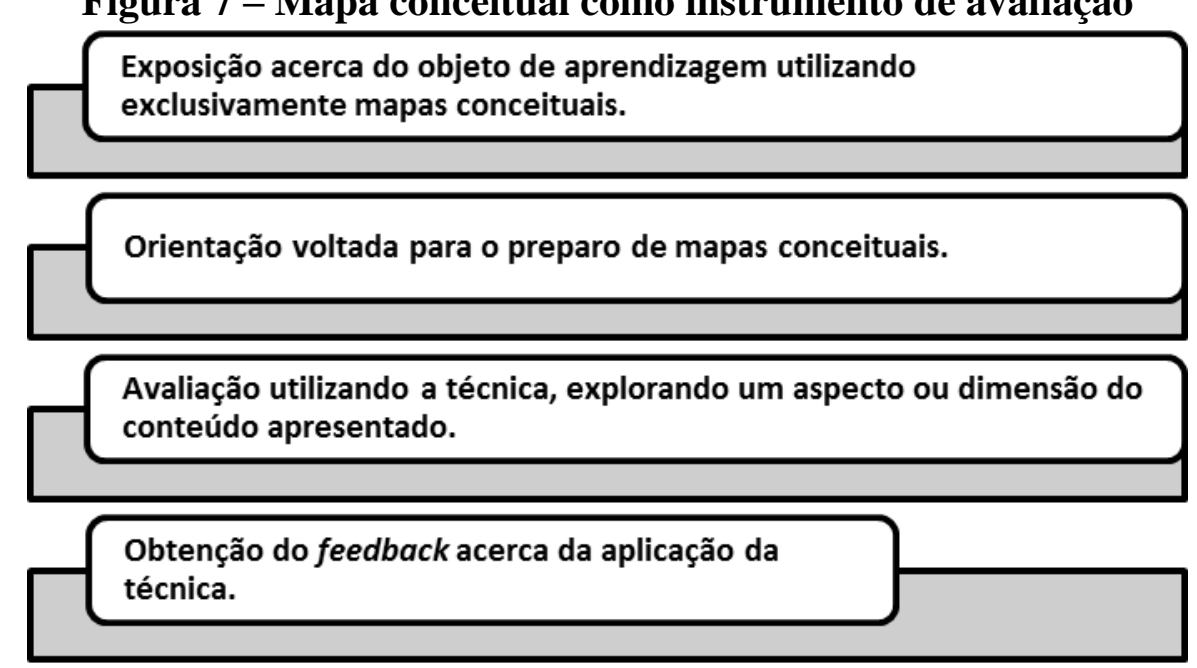

Fonte: elaborada pelos autores. 


\section{b) APLICAÇÃO NA DISCIPLINA DE ANÁLISE DE CUSTOS}

O ponto de partida da aplicação da técnica de mapeamento conceitual foi a orientação sobre o preparo de mapas conceituais.

Em seguida, os alunos foram seccionados em 4 grupos de 5 participantes.

Após essa exposição preliminar foi apresentada aos alunos uma 'situação - problema' utilizando os conceitos básicos de custos, sendo solicitado o preparo de mapas contendo um roteiro para sua solução, mediante construção coletiva negociada.

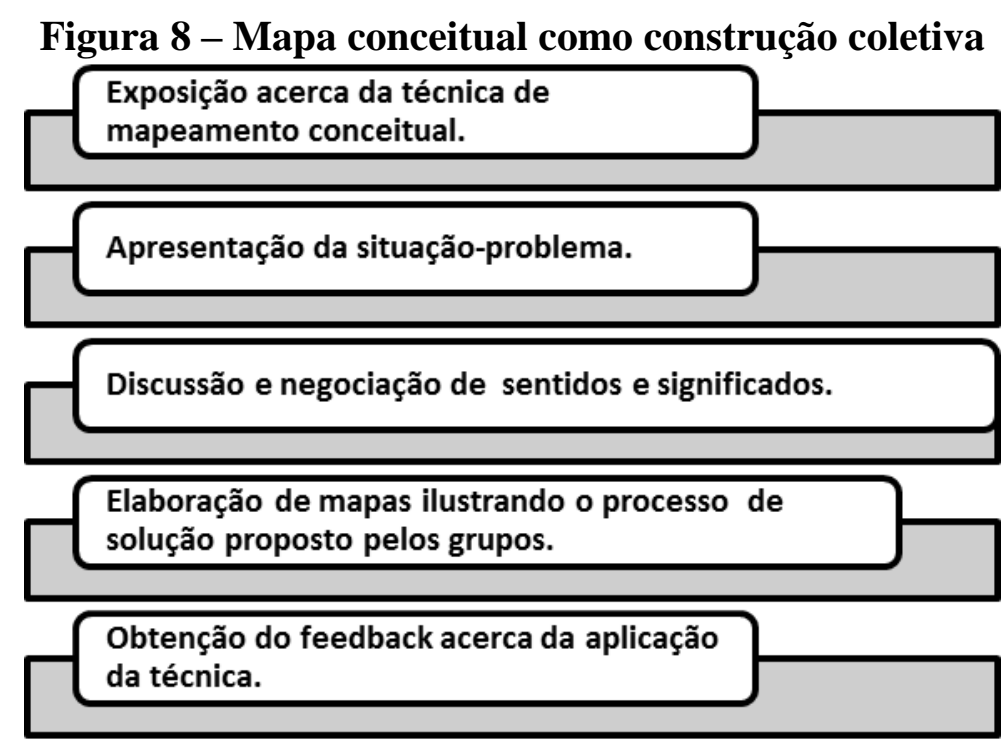

Fonte: elaborada pelos autores.

\subsection{ANÁLISE DE DADOS}

A análise empírica foi realizada a partir dos mapas elaborados por cada aluno e aquele construído coletivamente.

Quadro 2 - Matriz de análise dos mapas conceituais

\begin{tabular}{|l|}
\hline OBJETIVO DE APRENDIZAGEM \\
\hline ÊNFASE ATRIBUÍDA NA ELABORAÇÃO (no controle interno, na saúde financeira, por exemplo) \\
\hline $\begin{array}{l}\text { ELEMENTOS CONTEXTUAIS ADICIONADOS Ã CONSTRUÇÃO (fatores conjunturais e sociais de } \\
\text { influência) }\end{array}$ \\
\hline TIPOLOGIA DO MAPA (hierárquico, não hierárquico etc.) \\
\hline ALCANCE, PROFUNDIDADE E CLAREZA CONCEITUAL \\
\hline INFLUÊNCIAS IDENTIFICADAS \\
\hline CONVERGÊNCIA OU DIVERGÊNCIA DE PARADIGMAS \\
\hline
\end{tabular}

Fonte: elaborado pelos autores.

Os mapas conceituais produzidos foram analisados a partir da matriz de critérios, apresentada no quadro 2 .

\section{APRESENTAÇÃO E DISCUSSÃO DE RESULTADOS}

A análise dos mapas conceituais elaborados pelos sujeitos pesquisados ratifica os entendimentos e expectativas discutidas por teóricos em seus trabalhos, refletidas na revisão de literatura realizada. Por essa razão, optou-se por organizar as discussões a partir de enunciados. 
4.1 Os mapas conceituais, elaborados coletiva ou individualmente, revelam entendimentos, interesses, preconceitos, familiaridade, afinidades, inclinações, afiliações ideológicas, conhecimentos e experiências antigas e /ou recentes de seus autores.

Os aprendentes tenderam a apresentar seus mapas ou esquemas com base em interesses profissionais, afinidade temática, experiências e conhecimentos anteriores, especialmente aqueles mais recentes.

Os mapas conceituais elaborados denunciaram a preocupação do aprendente em manter-se numa 'zona de conforto', delimitada exatamente pelos conhecimentos preexistentes. A zona de conforto define-se como um campo de domínio, interesse e afinidade, fatores facilitadores da aprendizagem significativa. De fato, as representações mentais dos conceitos são foram naturalmente cuidadosas conservadoras.

Os mapas são espelhos mentais que comunicam a maneira como o aluno percebe e compreende sua realidade. Revela, igualmente, suas dificuldades de aprendizagem.

Observou-se, a partir da análise das relações conceituais estabelecidas pelos alunos, níveis diversos de complexidade e reflexões sobre o tema, o que ratifica uma característica dos mapas conceituais: a singularidade.

Os mapas conceituais, de fato, expressaram o modus de interpretação e organização dos conteúdos, suas trajetórias e atalhos de raciocínio, bem como dificuldades distintas, matéria-prima de intervenção pedagógica. Estilos e ênfases não são escolhas nascentes no vácuo, mas sim decorrentes de bases cognitivas.

A significação dos conteúdos mostrou-se essencialmente conservadora (inclusão de novos conceitos ao edifício cognitivo do indivíduo). Por essa razão, a familiaridade ganhou relevo no estabelecimento de relações interdisciplinares, trazendo conteúdos recentemente vivenciados por eles em disciplinas paralelas ou atuais.

As tentativas de desdobramento conceitual demonstraram esforço dos aprendentes em dirigir seu processo de aprendizagem, aproveitando um universo de informações mais amplo.

\subsection{Os mapas descerram dificuldades, entendimentos equivocados e o nível de} concentração dos discentes. Refletem, ainda, seu estado emocional.

Alguns alunos revelaram dificuldades de concentrar-se por motivos alheios à atividade (questões emocionais outras). De fato, o estado emocional afeta o envolvimento do aluno nas etapas de desenvolvimento da atividade, ensejando mudança de foco e dispersão. A concentração mobiliza e direciona o aparato cognitivo à realização da atividade, assim qualquer distração repercute objetivamente na qualidade do desempenho.

\subsection{A técnica de mapeamento conceitual mostrou-se como um instrumento interessante para o estabelecimento de associações interdisciplinares.}

As associações entre conceitos realizadas pelos alunos não se limitaram ao escopo da aula, incluindo conhecimentos de outras disciplinas não necessariamente afins, a exemplo de marketing e mercado de capitais.

Quando estimulados a refletir acerca de situações-problema com o propósito de propor soluções, os alunos acessam conhecimentos não necessariamente disciplinares. $\mathrm{O}$ escopo de análise é naturalmente ampliado para reforçar o sentido da proposta e consequentemente, a argumentação.

Essa observação constitui indício de que a técnica de mapeamento conceitual pode ser empregada em estratégias orientadas pelo objetivo de solucionar situações-problema ou, incorporando o olhar da Psicologia positiva, a análise de idealidades (situações positivas). Trata-se, então, de uma oportunidade de liberdade, onde o aluno estabelece de forma irrestrita pontes interdisciplinares, sem a clássica endogenia disciplinar. 
A liberdade é uma condição essencial à avaliação do desenvolvimento da aprendizagem. Intervenções ao longo do processo mascaram o desempenho, reduzindo significativamente o potencial diagnóstico da ferramenta.

Essas relações, ao serem incentivadas pelo docente em sua prática, dão sentido, coerência e unidade à grade curricular. A compartimentalização do conhecimento pode induzir o discente ao desprestígio de outras áreas à prejuízo do adequado preparo para lidar com situações complexas e multifacetadas. $\mathrm{O}$ manejo de conceitos complexos remete à esquemas cognitivos dotados de maior encadeamento, o que reclama uma visão interdisciplinar e abandono aos convencionalismos formais.

O enfoque excessivamente disciplinar culmina em visões 'parciais', unidirecionais e monoculares, desprovida de senso crítico, que não dá conta de problemas complexos.

A interdisciplinaridade é integradora, na medida em que descompartimentaliza saberes e promove sua sinergia. Com efeito, o 'pensar interdisciplinar' favorece o processo de subsunção conceitual, cerne da técnica de mapeamento, respeitando apenas a lógica dos nexos (POMBO, 2006; THIESEN, 2008; COIMBRA, 2000).

\subsection{Os mapas conceituais são úteis ao empreendimento de práticas colaborativas.}

A experiência de elaboração de mapas conceituais por equipes de trabalho oportuniza o desenvolvimento de habilidades de liderança, comunicação, negociação e diálogo construtivo, em um movimento de autodeterminação e independência, relativamente à influência do professor na condução das discussões. De fato, os grupos promoveram intensa discussão, não necessariamente convergente à construção (ou trilha) apresentada em aula pela docente da disciplina, incorporando experiências e conteúdos variados.

Nos mapas elaborados coletivamente, foram verificados elos em aberto e conceitos sem qualquer derivação. Os alunos atribuíram o isolamento desses 'nós conceituais' a não solução do conflito (produtivo) atinente à posição e significado do conceito naquela construção, o que criou a oportunidade de intervenção pedagógica docente visando o esclarecimento e mediação.

As características até aqui comentadas, no entendimento dos autores, favorecem sua aplicação em disciplinas contábeis com abordagem gerencial (Contabilidade gerencial, Análise de balanços, Análise de custos, Análise de investimentos, Análise financeira, etc.)

O mapeamento em grupo patrocina a troca de experiências e conhecimentos, contribuindo para o enriquecimento da construção e amadurecimento dos pares no convívio social.

\subsection{A liberdade na construção dos mapas estimula a criatividade.}

A variedade de trajetórias de interpretação observada diz muito sobre o nível de independência, organização do conhecimento e concatenação das ideias e conteúdos, objeto da disciplina. Revelam ainda, o 'inusitado' resultante da criatividade na mobilização dos recursos cognitivos disponíveis.

\subsection{Estilos cognitivos.}

O estilo cognitivo é um traço que torna o indivíduo singular. Os diferentes estilos cognitivos foram refletidos na configuração dos mapas, revelando em alguns casos impulsividade, noutros, cautela, dependência de juízo de valor, reflexão, níveis distintos de detalhamento, etc. Esses estilos são importantes porque influenciam a maneira como o indivíduo percebe, lê, interpreta e lida com a realidade, organizando-a e interiorizando as informações. 
Revista Ambiente Contábil - ISSN 2176-9036 - UFRN - Natal-RN. v. 9. n. 1, p. 117 - 143, jan./jun. 2017.

\subsection{A técnica auxilia em diagnósticos amplos, tendo em vista que comunicam o repertório do discente (seus schemas).}

Esses mapas apontam, a partir das formações conceituais, as fragilidades e dificuldades dos alunos, o que potencializa intervenções focadas nas mesmas, contrapondo-se às 'soluções genéricas' de pouca efetividade.

Em um dos mapas observou-se grande desorganização na construção (inexistência de relações coerentes, imprecisão e distanciamento da questão focal). As zonas de dispersão foram justificadas pelo esforço do aluno para concluir a tarefa. $O$ discente ratificou a existência de dificuldades e pouco domínio dos pré-requisitos da disciplina, o que tem repercutindo em sua motivação.

Essas dificuldades não se restringiram ao campo da técnica, alcançando fatores atitudinais e comportamentais: não comprometimento com a tarefa ou mesmo com a experiência de aprendizagem; desinteresse pelos conteúdos desenvolvidos; falta de motivação; ansiedade; resistência à técnica como expressão da preferência pela aula expositiva unidirecional; indisponibilidade ou prontidão para o diálogo com seus pares; inabilidade ou dificuldades de negociação. Um dos discentes informou preferir aulas 'ditadas' e 'comandadas' pelo professor, denunciando clara dependência.

As condições do aprendente e sua predisposição à experiência no processo de elaboração dos mapas influenciam sua qualidade.

O tempo disponível para a realização da atividade foi apontados como um dos fatores restritivos, especialmente na realização de mapeamentos em grupo.

Durante o processo de elaboração dos mapas pelas equipes, observou-se uma intensa e espontânea negociação de entendimentos e pontos de vista, todavia, em um dos grupos verificou-se iniciativas individuais de distanciamento, comprometendo as discussões naquela equipe. Essa experiência remete à conclusão de que, quando usado como técnica de ensino socializante, o mapeamento conceitual pode demandar do docente o empreendimento de intervenções visando provocar a interação.

\subsection{Visão e importância atribuída à disciplina (caso em tela, ANÁLISE DE CUSTOS e ANÁLISE DE BALANÇOS).}

Em alguns mapas, observou-se a tendência do respondente em reproduzir nos mapas, conceitos presentes em fórmulas ou memórias de cálculo, em detrimento de uma articulação e conexão conceitual mais ampla.

Constatou-se, ao conversar com os autores desses mapas que, esse direcionamento está diretamente relacionado com a visão que muitos alunos do curso de Administração (sujeitos da pesquisa) têm da Contabilidade: essencialmente normativa e presa aos objetivos fiscais, desvinculada do processo de tomada de decisão. Um dos alunos, inclusive, fez referência à Contabilidade como ciência exata, vinculando- a cálculos e formalidades procedimentais.

\subsection{Predominância de estrutura pouco complexas.}

Quanto à tipologia dos mapas conceituais construídos, foram observados dois tipos estruturais: hierarquizado (84\%) e de construção em rede (16\%). A escolha da estrutura refletiu a pouca maturidade dos autores.

\subsection{Intervenção e feedback acerca da aplicação da técnica}

A análise dos mapas conceituais ensejou um debate participativo sobre os conceitos desenvolvidos, onde os discentes tiveram a oportunidade de esclarecer dúvidas pontuais e inscrever novas discussões.

A exposição da docente (intervenção) foi configurada a partir das dificuldades percebidas, o que segundo os alunos foi fundamental para a compreensão do conteúdo. 
Revista Ambiente Contábil - ISSN 2176-9036 - UFRN - Natal-RN. v. 9. n. 1, p. 117 - 143, jan./jun. 2017.

Os alunos reconheceram a importância do instrumento. Um dos benefícios mais citados nos relatos diz respeito a liberdade do aluno no processo de mapeamento, sem limites disciplinares, o que fomenta abordagens mais amplas, aproveitando a contribuição de outras disciplinas.

\section{CONSIDERAÇÕES FINAIS}

O mapeamento une pensamento reflexivo e criatividade no processo de ensinoaprendizagem.

Ao ser utilizada como técnica de ensino, a ferramenta enseja a exploração do background e expertise do aprendente.

Os mapas conceituais oferecem uma visão integral (ampla) do conteúdo de aprendizagem, respeitando um padrão lógico de encadeamento a partir de relações paralelas ou hierárquicas.

Os resultados obtidos nesse estudo ratificam os benefícios pedagógicos referenciados na literatura que trata da matéria. De fato, os mapas:

- são úteis à prática de atividades colaborativas desenvolvendo habilidades sociais e de comunicação;

- favorecem o estabelecimento de conexões interdisciplinaridades e um aprendizado sem fragmentações;

- apresentam função diagnóstica, extrapolando os modelos clássicos de avaliação.

- revelam expertise, domínio, experiência, deficiências conceituais, fragilidades, descompromisso, etc.

A técnica de $\mathrm{O}$ processo de mapeamento é flexível (natureza híbrida), podendo ser enquadrado e aplicado como técnica de ensino individualizante ou socializante, consoante os propósitos de aprendizagem.

A análise dessa experiência destacou como fatores restritivos da eficácia da técnica de ensino: resistência à técnica, desinteresse pelo tema, descompromisso, conflitos improdutivos entre os pares, desvalor atribuído a disciplina, aversão a atividades em grupo, desmotivação, pouca concentração e foco e situações emocionais de desequilíbrio. O relato de experiência apresentado teve como principal restrição e desafio o tempo demandado para maturação da prática e aquele efetivamente disponível.

O pouco domínio do conteúdo a ser mapeado não foi considerado como restrição, mas como dado, cuja realidade demanda uma intervenção do docente.

Os mapas como técnica útil à prática pedagógica desvelam realidades não visíveis no cotidiano da sala de aula, trazendo à tona aspectos atitudinais, comportamentais e emocionais. Momentos diferentes geram mapas distintos, o que reforça sua importância como instrumento diagnóstico.

A ferramenta mostrou-se, igualmente, interessante no aproveitamento e sinergia de competências, integrando saberes intra e interdisciplinares. Identificar como o aluno pensa e organiza suas ideias tende a aumentar a eficácia das intervenções pedagógica, aproximando docentes e discentes.

Os mapas conceituais simbolizam a maneira como os conceitos estão mentalmente organizados. Assim, ao empregar a técnica de ensino, o docente mune-se de informações úteis para o desenho de atividades e tarefas bem como materiais didáticos potencialmente significativos.

A manipulação instrucional por meio de técnicas de ensino influencia os processos cognitivos compreendendo desde a organização dos conteúdos curriculares, estratégias adotadas e qualidade dos materiais didáticos ao comportamento do professor, dentro e fora da sala de aula. 
As estratégias de ensino devem, a priori, ser configuradas para dar lugar à elaboração de significados. Essa construção se dá de modo ativo (deliberado) e pessoal, por essa razão os mapas conceituais servem aos propósitos de avaliação. O potencial de significação, todavia, reclama atitudes, motivação e comportamentos proativos, favoráveis à aprendizagem.

As características do processo de significação ressaltam a argumentação de que o mapeamento auxilia à realização de sondagens, necessárias para a eficácia pedagógica. Esse diagnóstico preliminar oportuniza a elaboração de relações substantivas entre os conhecimentos prévios, ideias preexistentes e os dados da realidade que se descortina para exploração do sujeito. Desta forma importa à prática de planejamento, permitindo um trabalho pedagógico eficaz.

O tema, apesar de amplamente pesquisado, ainda carece de um enfoque mais pragmático, voltado para as peculiaridades da prática pedagógica. Esse quadro sugere a realização de novos estudos, explorando aspectos da operacionalização da teoria, afinal a aprendizagem configura-se como a apropriação de diferentes saberes ('saberes-fazer' e 'saberes-ser'), o que apresenta aos pesquisadores um amplo e complexo campo investigativo.

\section{REFERÊNCIAS}

ABRAHÃO, Maria Helena M. B. O modo dialógico de construir conhecimento. In: ABRAHÃO, Maria Helena M. B. Professores e alunos: aprendizagem significativa em comunidades de prática educativa. Porto Alegre, 2008.

ARAÚJO, Ana Marina Teixeira; MENEZES, CS de; CURY, Davidson. Um ambiente integrado para apoiar a avaliação da aprendizagem baseado em mapas conceituais. Anais do XII Simpósio Brasileiro de Informática na Educação, p. 49-58, 2002.

ARENAS, Agustín Campos. Mapas conceptuales, mapas mentales: y otras formas de representación del conocimiento. Coop. Editorial Magisterio, 2005.

AUSUBEL, D. P. Cognitive structure and the facilitation of meaningful verbal learning. Journal of Teacher Education, n. 14, p. 217-221, 1963.

BARBOSA, Márcio Lobo et al. Mapas conceituais na avaliação da aprendizagem significativa. Simpósio Nacional de Ensino de Física, v. 14, 2005.

BENGOECHEA, G. P. Una perspectiva constructivista de la enseñanza y el aprendizaje. España: Colegio Oficial de Psicólogos de Madrid, 2003.

BITTENCOURT, B. A. V. Mapas cognitivos e a pesquisa organizacional: explorando aspectos metodológicos. Brasil: Red Estudos de Psicologia, 2006.

CAÑAS, Alberto J. et al. Herramientas para construir y compartir modelos de conocimiento basados en mapas conceptuales. Revista de Informática Educativa, v. 13, n. 2, p. 145-158, 2000 .

CASTAÑEDA, Sandra Figueiras (Ed.). Evaluacion Del Aprendizaje en El Nivel Universitario. Elaboracion. UNAM, 2006. 
CASTAÑO, C. G., \& CALLES, D. A. M. Independencia de los estilos de aprendizaje de las variables cognitivas y afectivo motivacionales: Universidad Complutense de Madrid, 2000.

CARABETTA JÚNIOR, Valter. Using concept maps as a teaching resource for building and interrelating concepts. Revista Brasileira de Educação Médica, v. 37, n. 3, p. 441-447, 2013.

CICUTO, Camila Aparecida Tolentino; CORREIA, Paulo Rogério Miranda. Estruturas hierárquicas inapropriadas ou limitadas em mapas conceituais: um ponto de partida para promover a aprendizagem significativa. Aprendizagem Significativa em Revista, Porto Alegre, v. 3, n. 1, p. 1-11, 2013.

COIMBRA, José de Ávila Aguiar. Considerações sobre a interdisciplinaridade. Interdisciplinaridade em ciências ambientais, v. 1, 2000.

D’ÁVILA, Cristina. Por uma didática colaborativa no contexto das comunidades virtuais de aprendizagem. In: SANTOS, Edméa. ALVES, Lynn. Práticas pedagógicas e tecnologias digitais. Rio de Janeiro: E-papers, 2006.

DENZIN, N.K.; LINCOLN, Y.S. Handbook of qualitative research. Califórnia: Sage Publications, 2000.

DONGO-MONTOYA, Adrián Oscar. Teoria da aprendizagem na obra de Jean Piaget. São Paulo: UNESP, 2009.

ESCORIZA NIETO, José. Conocimiento psicológico y conceptualización de las dificultades de aprendizaje. Edicions Universitat Barcelona, 1998.

FAIRSTEIN, Gabriela Alejandra. GYSSELS, Silvana. Como se aprende? São Paulo: Edições Loyola, 2005.

FAGUNDES, T.C.P.C. Metodologia de pesquisa: especialização em EAD. Salvador: UNEB/EAD, 2009.

FAYOL, H. Administração industrial e geral. Tradução: Irene de Bojano e Mário de Sousa. 3.ed. São Paulo: Atlas, 1958.

FLICK, Uwe. Desenho da pesquisa qualitativa: Coleção Pesquisa qualitativa. Bookman, 2009.

FRANCO, Maria Amélia Santoro. Pedagogia da pesquisa-ação. Educação e pesquisa, v. 31, n. 3, p. 483-502, 2005.

FREIRE, P. Pedagogia da autonomia: saberes necessários à prática educativa. São Paulo: Paz e Terra, 1996. (Coleção Leitura).

GAVA, T. B. S.; MENEZES, C. S. de; CURY, D. Aplicações de mapas conceituais na educação como ferramenta metacognitiva. Anais... III International Conference on Engineering and Computer Education-ICECE. 16 a 19 de março de 2003 - UNISANTA. 
Revista Ambiente Contábil - ISSN 2176-9036 - UFRN - Natal-RN. v. 9. n. 1, p. 117 - 143, jan./jun. 2017.

GAVA, Tânia Barbosa Salles; MENEZES, CS de; CURY, Davidson. Aplicações de mapas conceituais na educação como ferramenta metacognitiva. Anais... In: III International Conference on Engineering and Computer Education-ICECE 2003. 2003.

GOLDENBERG, Mirian. A arte de pesquisar: como fazer pesquisa qualitativa em ciências sociais. 1997.

GUERRA, Isabel Carvalho. Pesquisa qualitativa e análise de conteúdo: sentidos e formas de uso. Lucerna, 2006.

KLIMENKO, O., \& ALVARES, J. L. Aprender cómo aprendo: la enseñanza de estrategias metacognitivas. Educación y Educadores, 2009, Volumen 12, Número 2, pp. 11-28. Colombia: D - Universidad de La Sabana, 2009.

KOTLER, P. Administração de Marketing. Tradução: Bazán Tecnologia e Linguística. ed. 10. São Paulo: Prentice Hall, 2000.

LABATUT, P. E. M. Aprendizaje universitario: un enfoque metacognitivo. Universidad Complutense de Madrid, 2000.

LESSA, R. K.; PINTO, A.C Cordeiro. Uso de mapas cognitivos no Ensino Superior. In: Anais do X Congresso Brasileiro de Ensino Superior a Distância-ESUD, X Congresso Brasileiro de Ensino Superior a Distância, UNIREDE. Belém / PA. 2013.

LÓPEZ, A. R. La estructuración del proceso de enseñanza y la investigación sobre el aprendizaje en el ser humano. Argentina: El Cid Editor | apuntes, 2009.

MARQUES, António Manuel de Miranda. Utilização pedagógica de mapas mentais e de mapas conceptuais. 2008.

MAYER, Richard E. Psicología de la educación: el aprendizaje en las áreas de conocimiento. Pearson Educación, 2002.

MAHONEY, Abigail Alvarenga; ALMEIDA, Laurinda Ramalho de. Afetividade e processo ensino-aprendizagem: contribuições de Henri Wallon. Psicologia da educação, n. 20, p. 11$30,2005$.

MARTÍNEZ, Lourdes Villalustre; DEL MORAL PÉREZ, María Esther. Mapas conceptuales, mapas mentales y líneas temporales: objetos' de'aprendizaje y'para'el aprendizaje en Ruralnet. RELATEC: Revista Latinoamericana de Tecnología Educativa, v. 9, n. 1, p. 1527, 2010.

MEZIROW, Jack. Visão geral sobre a aprendizagem transformadora. In: ILLERIS, Knud. Teorias contemporâneas da aprendizagem. São Paulo: Penso Editora, 2015.

MOREIRA, M. A. Linguagem e aprendizagem significativa. Conferência de encerramento do IV Encontro Internacional sobre Aprendizagem Significativa, Maragogi, AL, Brasil, 8 a 12 de setembro de 2003. 
MOREIRA, Marco Antônio; BUCHWEITZ, Bernardo. Mapas conceituais: instrumentos didácticos, de avaliaçao e de análise de currículo. Moraes, 1987.

MOREIRA, Marco Antônio; ROSA, Paulo. Mapas conceituais. Caderno Brasileiro de Ensino de Física, v. 3, n. 1, p. 17-25, 1986.

MOREIRA, Virgínia. De Carl Rogers a Merleau-Ponty: a pessoa mundana em psicoterapia. São Paulo: Annablume, 2007.

NOVAK, J. D.; A. J. CAÑAS, The theory underlying concept maps and how to construct and use them. Technical Report IHMC CmapTools 2006-01 Rev 01-2008, Florida Institute for Human and Machine Cognition, 2008.

NOVAK, Joseph D. Ayudar a los alumnos a aprender cómo aprender. La opinión de un profesor-investigador. In: Enseñanza de las Ciencias. 1991. p. 215-228.

NOVAK, Joseph Donald; GOWIN, D. Bob; OTERO, José. Aprendiendo a aprender. Barcelona: Martínez Roca, 1988.

ORELLANA, V. R. Mapas conceptuales y aprendizaje significativo. Argentina: El Cid Editor | apuntes, 2009.

PALMERO, Maria Luz Rodríguez. La teoría del aprendizaje significativo. In: PALMERO, Maria Luz Rodríguez (Org.). La teoría del aprendizaje significativo en la perspectiva de la psicología cognitiva. España: Ediciones Octaedro, S.L., 2010.

PEÑA, Antonio Ontoria (Ed.). Mapas conceptuales: una técnica para aprender. Narcea Ediciones, 1994.

PEREIRA, Duarte Costa. Nova educação na mova ciência para a nova sociedade: fundamentos de uma pedagogia científica contemporânea. Porto, Portugal: Universidade do Porto, 2007.

PERRAUDEAU, Michel. Estratégias de aprendizagem: como acompanhar os alunos na aquisição dos saberes. Porto Alegre: Artmed, 2009.

PÉREZ, G. B. . Enseñar y aprender en la universidad: claves y retos para la mejora. : Ediciones Octaedro, S.L., 2013.

PIAGET, J. A equilibração das estruturas cognitivas: problema central do desenvolvimento. Rio de Janeiro: Zahar, 1976.

POMBO, Olga. Interdisciplinaridade e integração dos saberes. Liinc em revista, v. 1, n. 1, 2006.

POZO, Juan Ignacio. Teorías cognitivas del aprendizaje. Madrid: Ediciones Morata, 1989. RESNICK, Lauren B.; COLLINS, Allan. Cognición y aprendizaje. Anuario de psicología, n. 69, p. 189-198, 1996. 
RODRÍGUEZ, Elaime Maciques. Trastornos del aprendizaje. Estilos de aprendizaje y el diagnóstico psicopedagógico. Infomed, Portal de Salud de Cuba, 2004.

RIBEIRO, Célia. Metacognição: um apoio ao processo de aprendizagem. Psicologia: reflexão e crítica, v. 16, n. 1, p. 109-116, 2003.

ROMAN, Jd. El puente de papel. Buenos Aires: LibrosEnRed, 2005.

RUIZ, H. Ó. D. Competencias comunicativas: proponer y argumentar. Colombia: Universidad Cooperativa de Colombia, 2006.

SAXE, Eleonora Badilla; MURILLO, Alejandra Chacón. Construccionismo: objetos para pensar, entidades públicas y micromundos. Actualidades investigativas en Educación, v. 4, n. $1,2011$.

SCHLEMMER, Eliane; SIMÃO NETO, Antonio. A construção de redes de significações: dos mapas conceituais aos "concept webbing". Anais... In: IX Congreso Iberoamericano de Informática Educativa-RIBIE, Caracas-Venezuela, Universidade de Caracas. 2008. p. 46-56.

SILVA, Luciana Saraiva da et al. Formação de profissionais críticos-reflexivos: o potencial das metodologias ativas de ensinoaprendizagem e avaliação na aprendizagem significativa. Formação de profissionais críticos-reflexivos, metodologias ativas e aprendizagem significativa. Revista del Congrés Internacional de Docència Universitària i Innovació (CIDUI), n. 2, 2015.

SHITSUKA, Ricardo; SILVEIRA, Ismar Frango; SHITSUKA, Dorlivete Moreira. Comparação entre as ferramentas Ontologia, Mapas Mentais e Mapas Conceituais na representação de conceitos em matriz curricular de curso de graduação. CRB-8 Digital, v. 4, n. 1, 2011.

SILVA, Maria Heloísa Aguiar. PEREZ, Isilda Louzano. Docência No Ensino Superior. Curitiba: iesde Brasil S/A, 2012.

STRAUSS, A.; CORBIN, J. Pesquisa qualitativa: técnicas e procedimentos para o desenvolvimento de teoria fundamentada. Porto Alegre: Artmed, 2008.

TAVARES, Romero. Construindo mapas conceituais. Ciências \& Cognição, v. 12, p. 72 85, 2007.

THIESEN, Juares da Silva. A interdisciplinaridade como um movimento articulador no processo ensino-aprendizagem. Revista Brasileira de Educação, v. 13, n. 39, p. 545, 2008.

THIOLLENT, Michel. Metodologia da pesquisa-ação. In: Metodologia da pesquisa-ação. Cortez, 2011.

TRIPP, David. Pesquisa-ação: uma introdução metodológica. Educação e pesquisa, v. 31, n. 3, p. 443-466, 2005.

TOZONI-REIS, M.F.C. Metodologia da pesquisa. Curitiba: IESDE, 2009. 
VASCONCELOS, C.; PRAIA, J. F.; ALMEIDA, L. S. Teorias de aprendizagem e o ensino/aprendizagem das ciências: da instrução à aprendizagem. Psicologia Escolar e Educacional, v. 7, n. 1, p.11-19, 2003.

VASCONCELOS, Yumara L. Função diagnóstica dos mapas conceituais no processo ensino-aprendizagem. Revista Tecnologias na Educação, n.13, dezembro de 20015.

VEIGA, Ilma Passos Alencastro. Ensinar, aprender, pesquisar e avaliar com mapas conceituais. In: VEIGA, Ilma Passos Alencastro (Org.). Novas tramas para as técnicas de ensino e estudo. Campinas, SP: Papirus, 2013.

VICTER, Eline das Flores; LOPES, Jurema Rosa; SOUZA, Antonio Carlos de. Uma discussão sobre a aprendizagem significativa: o ohar do professor e dos alunos. Almanaque Multidisciplinar de Pesquisa, v. 1, n. 2, 2015.

VIDAL-ABARCA, E., \& García, R. R. Aprendizaje y desarrollo de la personalidad. Larousse - Alianza Editorial, 2000. 